F. med. Genet. (1968). 5, 60.

\title{
Arrhinencephaly Associated with a Deficiency Involving Chromosome 18
}

\author{
A. McDERMOTT, J. INSLEY, MARGARET E. BARTON, PAMELA ROWE, \\ J. H. EDWARDS, and A. H. CAMERON
}

\author{
From the Institute of Child Health, Marston Green Hospital, East Birmingham Hospital, \\ and The Children's Hospital, Birmingham
}

\begin{abstract}
Bilateral harelip, cleft palate, and some form of arrhinencephalic malformation of the brain are among the more common striking features of trisomy 13-15. These cranio-facial malformations are attributable to a defect of the prechordal mesoderm, and the most extreme form consists of cyclopia associated with a monoventricular brain. The facial and cerebral malformations do not necessarily correspond to each other in severity. For example, in a recent analysis of seven cases of trisomy 13-15, one child (Case 4) showed no cleft of the lip or palate but had an extreme form of monoventricular arrhinencephaly (Snodgrass, Butler, France, Crome, and Russell, 1966).
\end{abstract}

Arrhinencephaly, with various degrees of involvement of the face and brain, is by no means confined to children with an abnormal karyotype. Landau, Barry, and Koch (1963) described severe cleft lip and palate associated with monoventricular arrhinencephaly in an infant with normal chromosomes. Cebocephaly, one of the more severe forms of this type of malformations, characterized by a single nostril and monoventricular arrhinencephaly has also been observed with a normal karyotype (De Myer, 1964). It is probable that such cases are reported less frequently than those with chromosomal abnormalities. N. E. France (personal communication, 1966) found that 4 out of 12 children with various types of arrhinencephaly had normal chromosomes; 6 showed trisomy 13-15, one trisomy 17-18, and one had a deficiency of part of the short arm of chromosome 5 .

De Myer, Zeman, and Palmer (1963) reported 2 sibs with median harelip, cleft palate, and monoventricular arrhinencephaly; the chromosomes of

Received May 5, 1967. one were examined and showed a normal karyotype. There is general agreement that children with arrhinencephaly and normal chromosomes have few other malformations. This is in contrast to those with trisomy 13-15 where extracephalic malformations are the rule.

The first published report of deficiency of the short arm of chromosome 18 was by de Grouchy, Lamy, Thieffry, Arthuis, and Salmon (1963), and there have been 12 other reports (Table I). These include 2 with some variety of the arrhinencephalic type of malformation of the face and brain. This paper described a further case, thus adding to the aetiological significance of the chromosomal deficiency.

\section{Case Report}

This male infant was born 12 days before term to a gravida-2 mother aged 25 years. Pregnancy was uneventful; delivery was by forceps because of foetal distress. The baby weighed $2.48 \mathrm{~kg}$. ( $5 \frac{1}{2} \mathrm{lb}$.) at birth, and measured

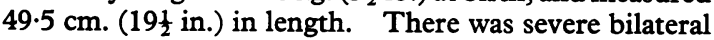
cleft lip and palate, with flattening of the nose, close-set eyes, and unusual configuration of the ears (Fig. 1 and 2). The skull circumference was smaller than normal, $30 \mathrm{~cm}$. (113 in.). The penis was short, approximately $0.6 \mathrm{~cm}$. ( $\frac{1}{4}$ in.) in length, but the scrotum was normal and contained palpable testes (Fig. 3). The limbs showed no abnormality. He died from pneumonia at the age of 6 days.

Necropsy. Externally the above features were confirmed. The skull showed overlapping of the sutures with obliteration of the fontanelles. Internal examination showed basal consolidation of the lungs but no other abnormality of the thoracic and abdominal viscera and in particular no malformation. The pituitary, thyroid, and adrenal glands were unremarkable. The brain was 60 
TABLE I

REPORTED CASES OF SHORT ARM DEFICIENCY CHROMOSOME 18

\begin{tabular}{|c|c|c|c|c|c|c|c|c|c|c|}
\hline & Age & Sex & $\underset{\text { Mental }}{\text { Retarda- }}$ & $\underset{\text { ism }}{\text { Dwarf- }}$ & Caries & $\begin{array}{l}\text { Ocular } \\
\text { Abnor- } \\
\text { malities }\end{array}$ & $\begin{array}{c}\text { Ab- } \\
\text { normal } \\
\text { Ears }\end{array}$ & $\begin{array}{l}\text { Small } \\
\text { Man- } \\
\text { dible }\end{array}$ & Webbing & $\begin{array}{l}\text { End. } \\
\text { Dis- } \\
\text { orders }\end{array}$ \\
\hline $\begin{array}{l}\text { Without proven arrhinencephaly } \\
\text { Edwards and Clarke, personal com- } \\
\text { munication (1960) } \\
\text { de Grouchy et al. (1963) } \\
\text { Lewis, Poulding, and Woods (1963) } \\
\text { Dill and Miller (1963) } \\
\text { Bühler, Bühler, and Stalder (1964) } \\
\text { Hickox (1964) } \\
\text { Summitt (1964) } \\
\text { Van Dyke, Valdmanis, and Mann } \\
\text { (1964) } \\
\text { Uchida et al. (1965), Case } 1 \\
\text { "', ", ", ", Case } 2 \\
\text { Present report, mother (1967) } \\
\text { With proven arrhinencephaly } \\
\text { Uchida et al. (1965), Case 3 } \\
\text { Faint and Lewis (1964) } \\
\text { Present report, infant (1967) }\end{array}$ & $\begin{array}{l}1 \mathrm{yr} . \\
6 \mathrm{yr} . \\
33 \mathrm{yr} . \\
1 \mathrm{yr} 9 \mathrm{mth} . \\
3 \mathrm{yr} . \\
4 \mathrm{yr} . \\
5 \mathrm{yr} . \\
16 \mathrm{yr} . \\
1 \text { yr. } 4 \mathrm{mth} . \\
31 \mathrm{yr} . \\
25 \mathrm{yr} . \\
3 \mathrm{dy} . \\
1 \mathrm{dy} . \\
6 \mathrm{dy} .\end{array}$ & $\begin{array}{l}\text { M } \\
\mathbf{M} \\
\mathbf{M} \\
\mathbf{F} \\
\mathbf{F} \\
\mathbf{F} \\
\mathbf{F} \\
\mathrm{F} \\
\mathbf{M} \\
\mathrm{F} \\
\mathbf{F} \\
\mathrm{F} \\
\mathbf{F} \\
\mathbf{M}\end{array}$ & $\begin{array}{l}+ \\
+ \\
+ \\
+ \\
+ \\
+ \\
+ \\
+ \\
+ \\
+ \\
+\end{array}$ & $\begin{array}{l}+ \\
- \\
+ \\
+ \\
+ \\
+ \\
+ \\
+ \\
+ \\
+ \\
+\end{array}$ & $\begin{array}{l}- \\
+ \\
+ \\
+ \\
+ \\
+ \\
+ \\
+ \\
+\end{array}$ & $\begin{array}{l}- \\
+ \\
+ \\
+ \\
+ \\
+ \\
+ \\
+ \\
+ \\
- \\
+ \\
+ \\
+\end{array}$ & $\begin{array}{l}\overrightarrow{+} \\
+ \\
+ \\
+ \\
+ \\
+ \\
+\end{array}$ & $\begin{array}{l}+ \\
+ \\
-\end{array}$ & $\begin{array}{l}+ \\
- \\
+ \\
+ \\
+ \\
+ \\
- \\
-\end{array}$ & $\begin{array}{l}+ \\
+ \\
+ \\
- \\
- \\
+ \\
+ \\
+\end{array}$ \\
\hline
\end{tabular}

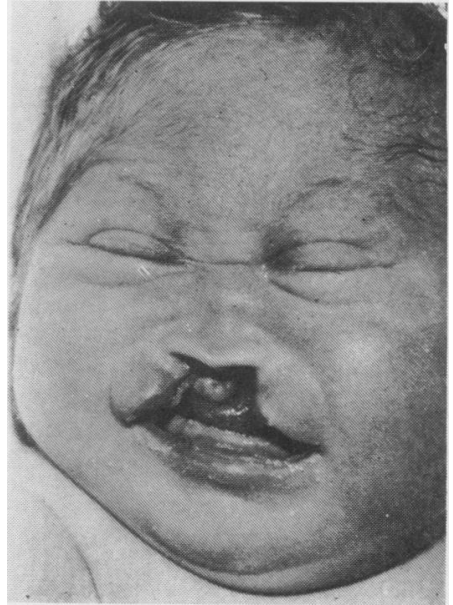

FIG. 1. Note the close-set eyes, the bilateral harelip, and the cleft palate, with a rudimentary premaxillary process isolated in the midline.

normal of $307 \mathrm{~g}$. The cerebral hemispheres were greatly reduced in size and were symmetrical. They were foreshortened so that the transverse diameter of the brain $(9.8 \mathrm{~cm}$.) was greater than the maximum antero-posterior measurement $(7 \cdot 8 \mathrm{~cm}$.) (Fig. 4). The fronto-parietal lobes were virtually non-existent and were represented by a small mass in the midline anteriorly, which was divided by a well-defined median sulcus. Posterior to this, the cerebral tissue showed no median sulcus, and the total antero-posterior measurement in the midline was $4.4 \mathrm{~cm}$. The occipital lobes were small with three prominent gyri widely separated by deeply indented sulci. The temporal lobes were relatively well formed, and on either side they extended approximately $1.5 \mathrm{~cm}$. anterior to the hypoplastic frontal region (Fig. 5). Both showed broad medial and lateral gyri. On the inferior surface in the midline the cerebral peduncles appeared to be fused together. The major arteries

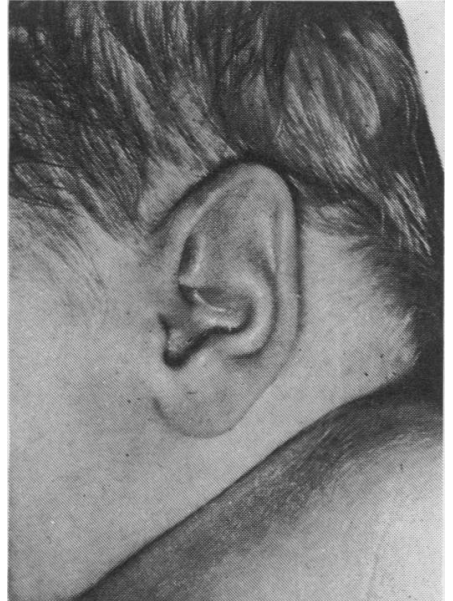

FIG. 2. The upper part of the helix shows a curious angulation.

appeared to follow a normal course. There were no olfactory bulbs or tracts, nor was there any evidence of the trigone. The optic nerves and chiasma appeared

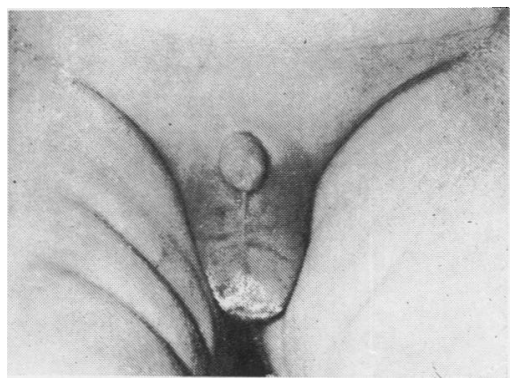

Fig. 3. Hypoplasia of the penis. 
Fig. 4. Brain, inferior surface. The temporal lobes are relatively well developed and constitute the most anterior part of the brain.

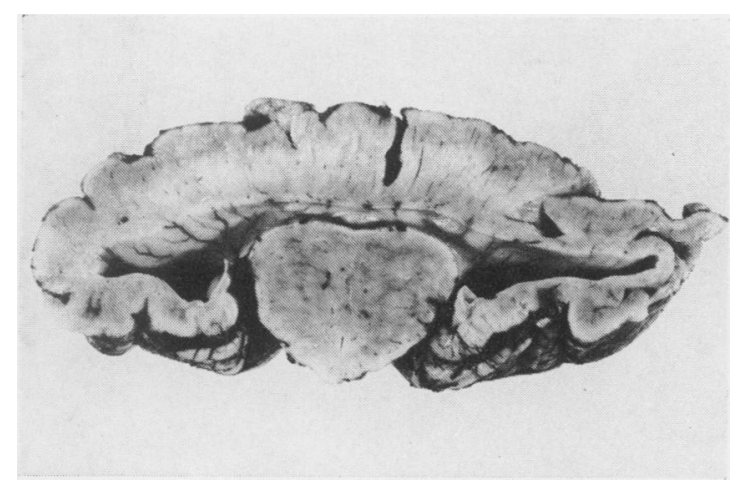

Fig. 6. Coronal slice through the brain at the level of the fused basal ganglia. The lateral ventricles form an undivided cavity, and the third ventricle is represented by the small cleft seen in midline at the bottom of the picture.

normal as did the remainder of the nerve roots. A preliminary transverse slice through the cerebral hemispheres showed a single ventricular cavity (Fig. 6). The basal ganglia and cerebral peduncles were represented by a single pear-shaped mass in the inferior part of which

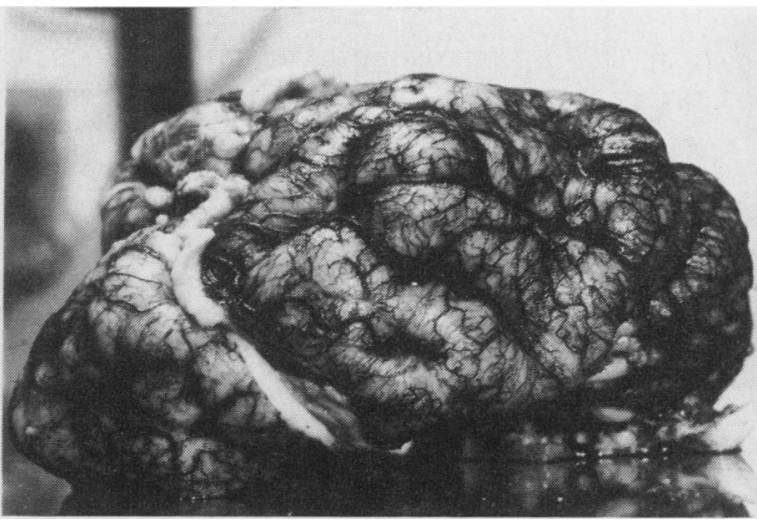

Fig. 5. Left lateral aspect of brain showing well-developed temporal gyri. The occipital lobes are small and do not cover the cerebellum which lies on the right of the picture.

was a slit-like cavity $0.5 \mathrm{~cm}$. in length, representing the 을 third ventricle. No communication between this and the superior ventricle could be identified. Well- 3 developed tufts of choroid plexus were situated on the postero-lateral aspects of the fused midline mass. The $\frac{\widehat{O}}{\square}$ brain-stem and cerebellum appeared to be well developed $\vec{\bullet}$ and showed no external malformations. The pia- $\mathscr{D}$ arachnoid was highly vascular, and over the Sylvian fissures and the hypoplastic frontal region it was very slightly thickened. It is proposed to make a further report of the detailed histological appearances.

Family History. The mother had one other pregnancy three years previously which ended in a miscarriage at 12 weeks. The conceptus was not examined. There is no history of malformation in the large parental sibships (Fig. 7).

\section{Chromosome Studies}

Observations. Chromosome analyses were performed on preparations from lymphocyte cultures of those members of the family indicated in Fig. 7. The propositus was found to have a male karyotype with normal chromosomes in all groups except the 17-18

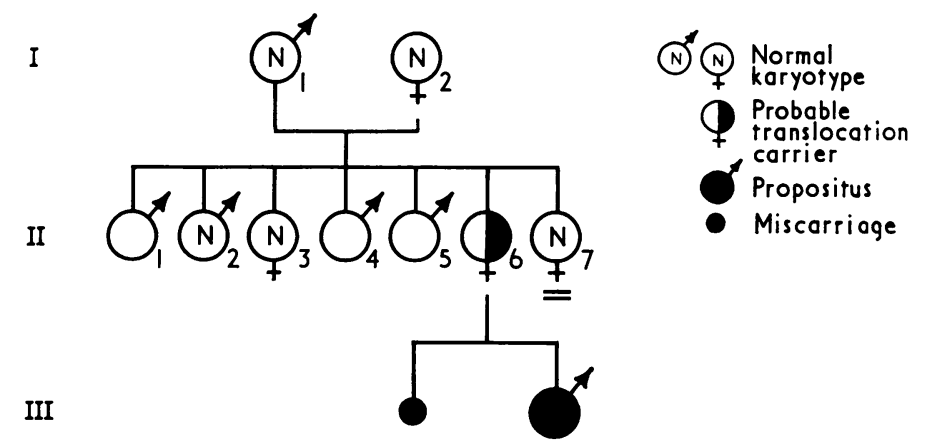

FIg. 7. The distaff side of the family tree. 


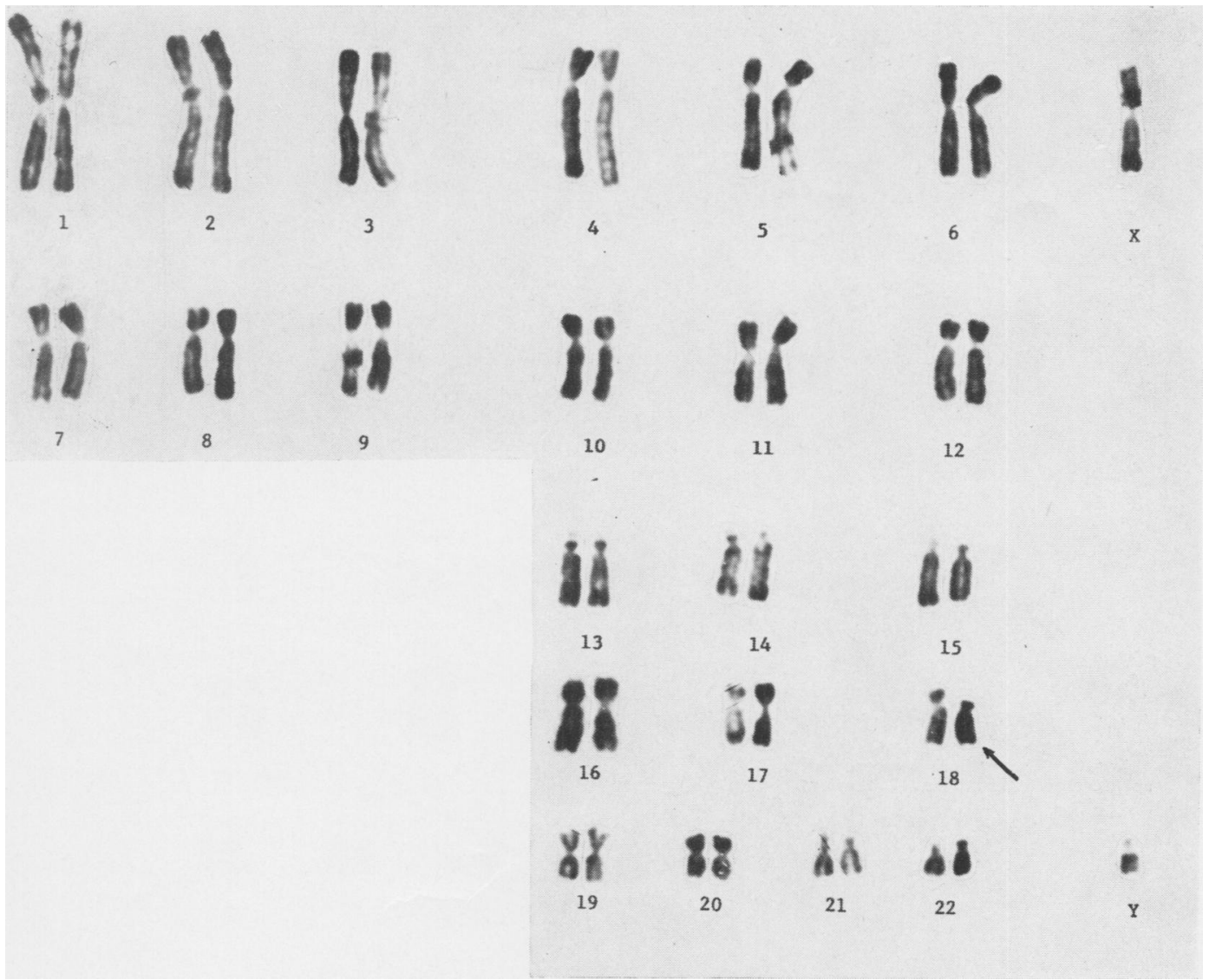

FIG. 8. The patient's karyotype. An arrow indicates the short arm deletion.

group, in which one chromosome 18 had short arms of about half the normal length (Fig. 8). The mother was found to have an apparently identical karyotype (Fig. 9). Both maternal grandparents (I. 1 and I. 2) and the maternal relatives available (II. 2, II. 3, and II. 7) had normal karyotypes.

Interpretation. There are two ways in which the observed abnormalities could have given rise to arrhinencephaly in the infant without affecting the mother. Both assume that the structural change in the chromosome occurred either during gametogenesis in one grandparent, or early in the development of the mother.

(1) The mother may be a balanced structural heterozygote for a reciprocal translocation between the short arm of chromosome 18 and some longer chromosome on which the small amount of additional material cannot be detected in the chromosomes in mitosis. The infant receiving only one of the translocation chromosomes would then be an unbalanced structural heterozygote (Fig. 10), with either an excess or a deficiency of chromosome material. The latter would produce the karyotype observed in the patient. If the abnormal chromosome does not upset segregation at meiosis, there would be a one in four chance of a gamete carrying the abnormality. However, due to preferential abortion of abnormal embryos, the risk of a birth with this anomaly might be far less.

(2) The abnormal chromosome in the infant may be the result of two chromosomal events, the second being a consequence of the first.

The abnormal chromosome 18 in the mother may have resulted from a pericentric inversion, probably in a mitotic interphase during her early embryogenesis. This would cause shortening of the short arm and lengthening of the long arm without alteration of the genetic content (Fig. 11).

Complete synapsis of the inverted chromosome in meiosis would only be possible by the formation of an inversion loop (Fig. 12). Genetic crossing-over within this loop could produce unbalanced chromosomes. The example illustrated in the figure shows how a single cross-over may cause the inverted chromosome with the abnormal short arm to lose a segment from its long arm, while its normal partner gains a segment on its long arm.

The total effect of these processes is twofold. First 

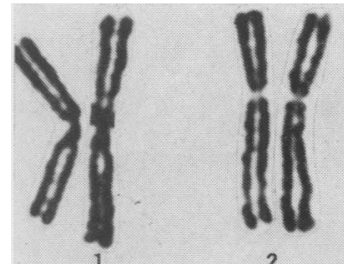

2

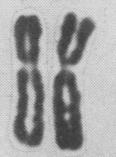

7

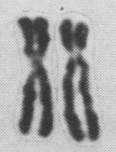

8

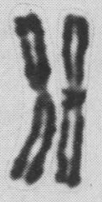

3

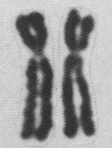

9

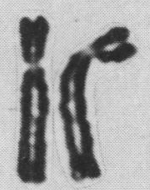

4

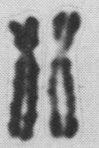

10

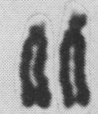

13

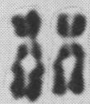

FIG. 9. The mother's karyotype is apparently identical to that of the infant.
16

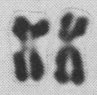

19

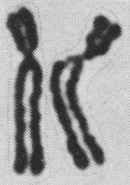

5

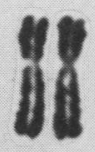

11

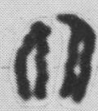

14

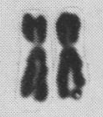

17

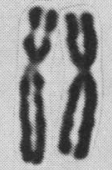

6

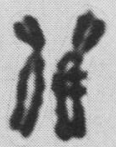

12

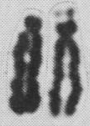

15

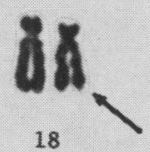

18

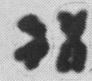

20

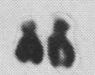

21

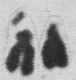

22

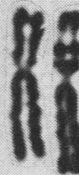

x
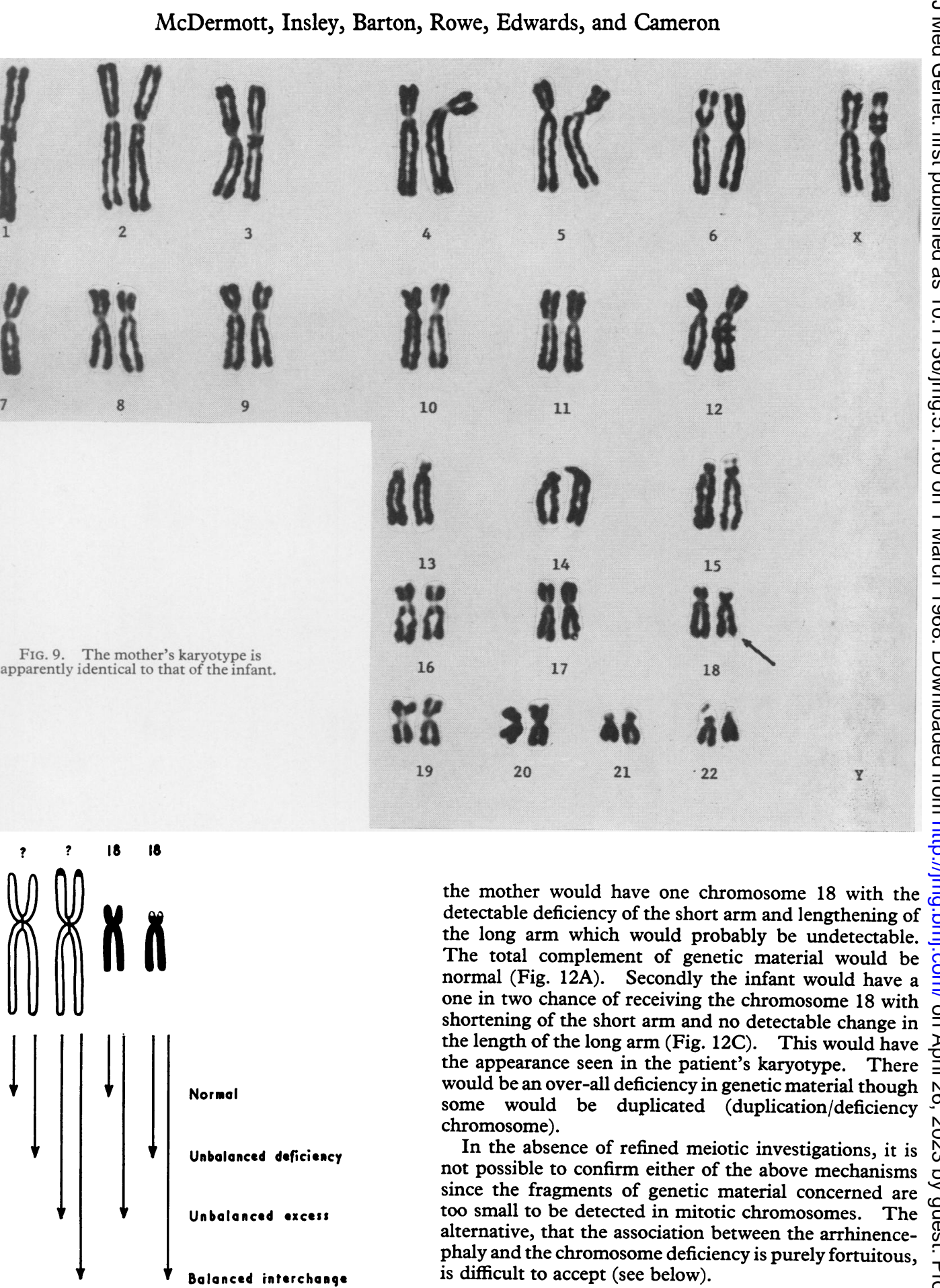

Fig. 10. First possible interpretation of the cytological findings. The maternal chromosomes illustrate a balanced reciprocal translocation with an unidentified large chromosome, and the arrows indicate the possibilities during gametogenesis. the mother would have one chromosome 18 with the detectable deficiency of the short arm and lengthening of the long arm which would probably be undetectable. The total complement of genetic material would be normal (Fig. 12A). Secondly the infant would have a one in two chance of receiving the chromosome 18 with shortening of the short arm and no detectable change in the length of the long arm (Fig. 12C). This would have the appearance seen in the patient's karyotype. There would be an over-all deficiency in genetic material though some would be duplicated (duplication/deficiency chromosome). not possible to confirm either of the above mechanisms since the fragments of genetic material concerned are too small to be detected in mitotic chromosomes. The alternative, that the association between the arrhinencephaly and the chromosome deficiency is purely fortuitous, is difficult to accept (see below).

Blood Film. No abnormality was seen and in particular the polymorphs showed no drumsticks and no excess in the number of nuclear projections.
In the absence of refined meiotic investigations, it is 
(II)
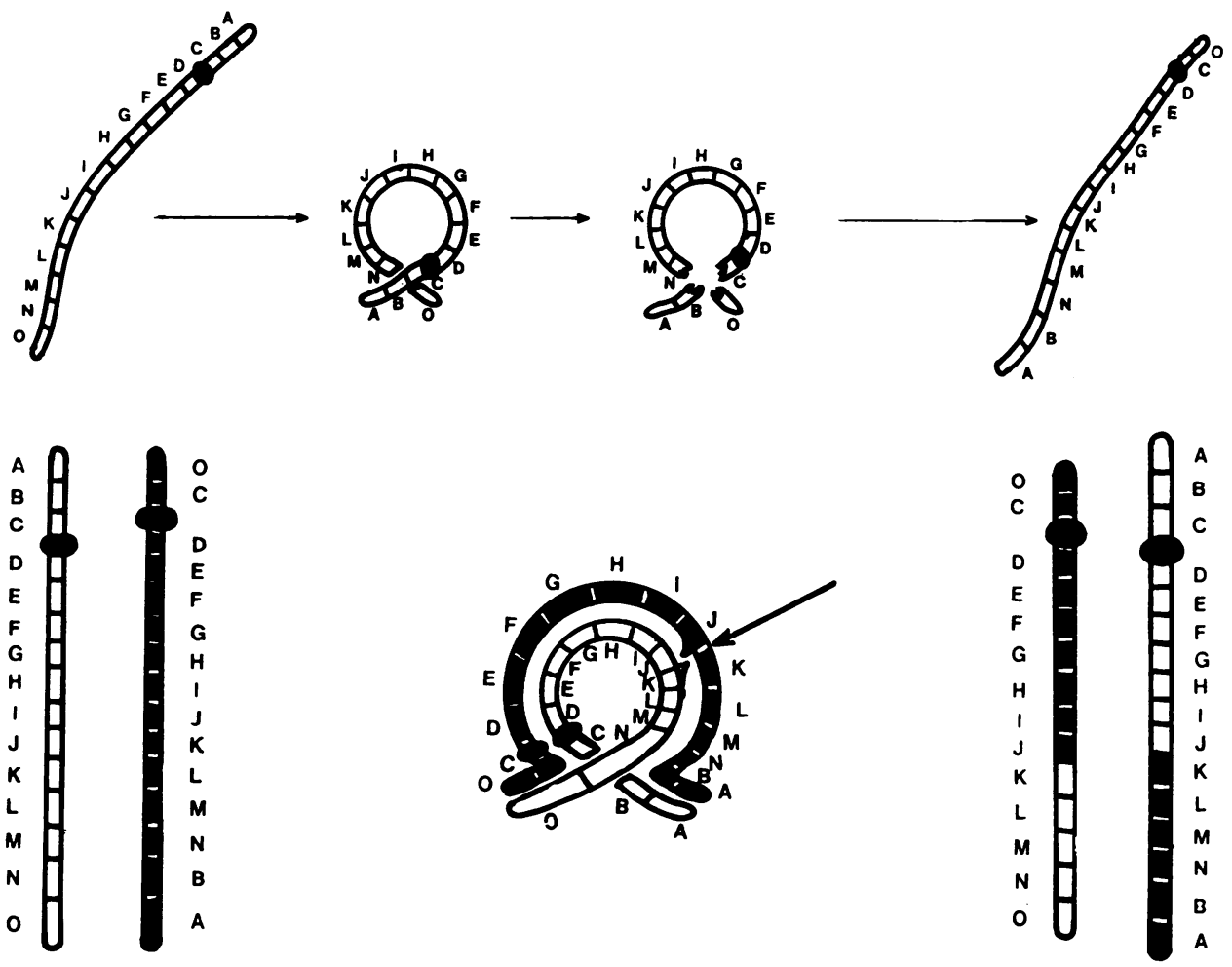

A

B

C

Fig. 11 and 12. The second possible interpretation of the cytological findings. (11) Pericentric inversion during mitosis in the mother with transfer of material from the short to the long arm of chromosome 18. (12) The formation of an inversion loop during meiosis in a maternal oocyte. This produces two duplication/deficiency chromosomes (C), one of which shows shortening of the short arm. The arrow in $B$ indicates a possible site of breakage and interchange.

Linkage Data. Extensive studies of blood groups carried out by Drs. Race and Sanger, and of serum groups and red cell enzymes by Professor Harris and Dr. Robson, showed no abnormality in segregation (Table II). The presence of the-D-D-chromosome, which may be related to a deficiency in the rhesus complex, is probably fortuitous, particularly since it segregates independently. However, the rarity of both conditions may justify further studies on persons carrying this chromosome. It is known from other cases that the rhesus locus is not on the short arm of chromosome 18, assuming that a distinction between chromosomes 17 and 18 is possible (J. H. Edwards and S. O. Lawler, personal communication, 1960; Salmon, Ropartz, de Grouchy, Lejeune, Salmon, Rivat, Rousseau, Liberge, and Delarue, 1966). It is clear from Table II that the part of the chromosome which is deficient is not related to the loci determining the $M N$, rhesus, or red cell acid phosphatase phenotypes.

\section{Discussion}

This case is the third reported example of arrhinencephaly associated with a deficiency of the short arm of chromosome 18.

The first was originally thought to have normal chromosomes (Haworth, Medovy, and Lewis, 1961; Case 1), but later examination showed the deficiency (Uchida, McRae, Wang, and Ray, 1965; Case 3). She was an infant with cebocephaly, closeset eyes, and choanal atresia. The anterior fontanelle was small and there was marked overriding of the sutures. The brain was $50 \%$ of normal weight and the cerebrum showed no division into hemisspheres. It contained a single ventricle with fused thalami in its floor, and the posterior half of the cerebrum was represented by a cystic cavity. 
TABLE II

LINKAGE DATA

\begin{tabular}{|c|c|c|c|c|c|c|c|c|c|c|c|c|c|c|c|c|c|c|c|c|c|c|}
\hline \multirow{3}{*}{\begin{tabular}{|c|}
\multicolumn{1}{|c|}{$\begin{array}{c}\text { Identity } \\
\text { with } \\
\text { pedigree } \\
\text { designation }\end{array}$} \\
Maternal \\
Grandmother \\
I. $_{\cdot 2}$
\end{tabular}} & \multicolumn{14}{|c|}{ Red Cell Antigens } & \multicolumn{4}{|c|}{ Serum Types } & \multicolumn{4}{|c|}{ Red Cell Enzymes } \\
\hline & ABO & MNSs & $P_{1}$ & $\mathbf{R h}$ & $\mathrm{Lu}^{\mathrm{a}}$ & $\mathrm{K}$ & $\mathrm{Le}^{\mathrm{a}}$ & $L e^{b}$ & $\mathrm{Fy}^{\mathrm{a}}$ & $F_{y}{ }^{b}$ & $\mathrm{Jk}^{\mathrm{a}} \mathrm{Jk}$ & $\mathbf{J}^{\mathbf{b}}$ & $\mathbf{X g}^{\mathbf{a}}$ & $\mathrm{Do}^{\mathrm{a}}$ & $\mathrm{Hp}$ & Tf & $\mathbf{C}_{5}$ & UIA & $\mathrm{AcPh}$ & PGM & 6-PGD & AK \\
\hline & o & MMSs & + & cde/-D- & - & - & & & + & + & & & + & & & C & - & $\mathbf{U}$ & BA & $2 \cdot 1$ & A & 1 \\
\hline $\begin{array}{l}\text { Maternal } \\
\text { Grandfather } \\
\mathbf{I}_{\cdot 1}\end{array}$ & O & MMss & - & $\mathrm{CDe} / \mathrm{CDe}$ & - & - & - & - & + & + & + & - & + & + & $2 \cdot 2$ & C & + & $\mathrm{U}$ & BA & 1 & A & 1 \\
\hline $\begin{array}{l}\text { Maternal } \\
\text { Uncle II.2 }\end{array}$ & o & MMSs & + & $\mathrm{CDe} /-\mathrm{D}-$ & - & - & + & - & + & + & + & + & - & - & $2 \cdot 2$ & C & - & & $\mathrm{BA}$ & 1 & & 1 \\
\hline $\begin{array}{l}\text { Maternal } \\
\text { Aunt II.3 }\end{array}$ & O & MMSs & + & $\begin{array}{l}\mathrm{CDe} / \mathrm{cde} \\
\text { or cDe }\end{array}$ & - & - & & & + & + & + & + & + & + & $2 \cdot 1$ & $\mathrm{C}$ & - & & A & $2 \cdot 1$ & & 1 \\
\hline $\begin{array}{l}\text { Maternal } \\
\text { Aunt } \quad \text { II. }\end{array}$ & O & MMSs & - & $\begin{array}{l}\mathrm{CDe} / \text { cde } \\
\text { or } \mathrm{cDe}\end{array}$ & - & - & - & - & + & + & ++ & + & + & + & $2 \cdot 1$ & C & + & $\mathbf{U}$ & B & $2 \cdot 1$ & A & 1 \\
\hline Mother II. 6 & o & MMss & + & $\mathrm{CDe} /-\mathrm{D}-$ & - & - & + & - & + & - & + & + & + & - & $2 \cdot 1$ & C & - & $\mathbf{U}$ & A & $2 \cdot 1$ & A & 1 \\
\hline Father & $\mathbf{A}_{2}$ & $\mathrm{MN}$ & & $\mathrm{CDe} / \mathrm{cde}$ & & - & & & & & & & + & & $2 \cdot 2$ & C & - & $\mathrm{U}$ & B & 1 & A & 1 \\
\hline Child & o & $\mathrm{MN}$ & & $\begin{array}{l}\mathrm{CDe} /-\mathrm{D}- \\
\text { or CDe* }\end{array}$ & & - & & & & & & & + & & o & C & - & $\mathbf{U}$ & BA & 1 & A & 1 \\
\hline
\end{tabular}

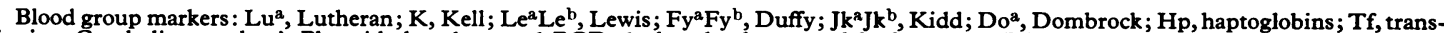
ferrins; $\mathrm{C}_{5}$, cholinesterole; $\mathrm{AcPh}$, acid phosphatase; 6-PGD, 6-phosphogluconate dehydrogenase; PGM, phosphoglucomutase; AK, adenylatekinase.

$\star$ The distinction was not made because the child died before the presence of -D- in the family was known.

The olfactory bulbs, nerves, tracts, and striae were absent. There was a mass of fibrous tissue in the infundibular region and the pituitary was not found. The adrenals were extremely small and resembled those in anencephaly, and there was also hypoplasia of the thyroid. The mother and her second child, a boy, were mentally retarded and appeared similar to other reported cases of short arm deficiency of chromosome 18 (see Table I). The mother showed mosaicism for this deficiency while the second child showed the deficiency, in all cells observed.

The second was briefly reported by Faint and Lewis (1964). This was a female cyclops (Fig. 13) with a small arrhinencephalic brain, the fused cerebral hemispheres being largely represented by a single fluid-filled sac. In this case, too, the pituitary was absent, the adrenals were like those in anencephaly, and there was hypoplasia of the thyroid. The karyotype of the mother was normal, but the father showed a presumptive deficiency of one of the 13-15 chromosomes (S. Faint and F. J. W. Lewis, personal communication, 1967). The short arms of this group, as opposed to those of the 17-18 chromosomes, have a wide normal variation, and we would agree with these authors that it is possible that the deficiency in the father may have no bearing on the findings in the infant.
Eleven cases with deletion of the short arm of chromosome 18, but without arrhinencephaly, have been reported (Table I). The majority are females and the ages at diagnosis ranged from 16 months to 33 years. All except the mother of the case reported here have been mentally retarded. Almost all have been short in stature and have shown dental caries and abnormalities of the eyes, such as close-set eyes, hypertelorism, ptosis, and epicanthic folds. Less common features include low-set ears, a small mandible, and webbing of the neck. Two of the adults have shown hypothyroidism which is of interest in view of the necropsy findings in the cases described by Faint and Lewis (1964) and by Haworth et al. (1961: Case 1). Apart from these endocrinological features, and even assuming that the mental retardation is an indication of a cerebral maldevelopment, there is little resemblance between the 3 infants with arrhinencephaly and these 11 cases which appear to have the same deletion of chromosome 18.

However, the occurrence of 3 such cases with a similar deletion is hardly likely to be a simple coincidence. It appears that this deletion predisposes to a somewhat poorly defined clinical entity having the features described above, and also produces a peculiar susceptibility to the development of arrhinencephaly. There is little to com- 


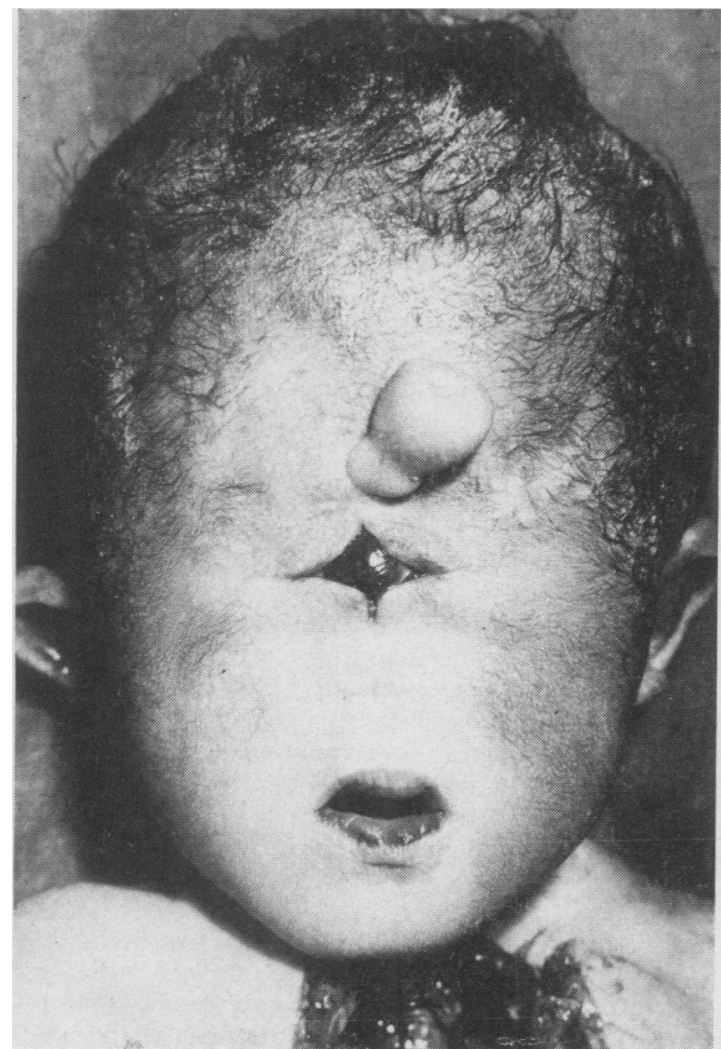

FIG. 13. Face of the intant reported by Faint and Lewis (1964). The appearances are those of the cyclopian form of arrhinencephaly. We are particularly indebted to the authors for their kindness in allowing the publication of the photograph and providing information given in the text.

mend the suggestion made by Uchida et al. (1965) that this additional malformation is due to a recessive lethal gene, presumably situated on the short arm of the intact chromosome 18 . One must be cautious in accepting such a purely genetic explanation, as reports of sibships with arrhinencephaly (De Myer et al., 1963; Klopstock, 1921) are extremely rare and environmental factors are known to be operative in animals. For example, Binns, James Shupe, and Thacker (1962) found that the cyclopian malformations in lambs, previously considered to be hereditary, were due to the ingestion of a plant, Veratrum californicum.

\section{Summary}

An infant is described with severe arrhinencephalic malformations of the face and brain and deficiency of part of the short arm of a chromosome 18. The parents appear to be normal but the mother has an apparently identical deficiency.

It is concluded that the deficiency predisposes to a syndrome which includes mental retardation, dwarfism, and ocular abnormalities, as well as an increased susceptibility to develop arrhinencephaly.

It is postulated that the mother possesses a normal amount of genetic material, having either a balanced reciprocal translocation or a pericentric inversion involving chromosome 18. Either could produce a karyotype apparently indistinguishable from that of the infant in mitotic preparations.

\section{REFERENCES}

Binns, W., James, L. F., Shupe, J. L., and Thacker, E. J. (1962). Cyclopian-type malformation in lambs. Arch. environm. Hlth, 5, 106.

Bühler, E. M., Bühler, U. K., and Stalder, G. R. (1964). Partial monosomy 18 and anomaly of thyroxine synthesis. Lancet, 1, 170. de Grouchy, J., Lamy, M., Thieffry, S., Arthuis, M., and Salmon, C. (1963). Génétique-dysmorphie complete avec oligophrénié: délétion des bras courts d'un chromosome 17-18. C.R. Acad. Sci. (Paris), 256, 1028.

De Myer, W. (1964). A 46 chromosome cebocephaly, with remarks on the relation of 13-15 trisomy to holoprosencephaly (arhinencephaly). Ann paediat. (Basel), 203, 169.

- Zeman, W., and Palmer, Catherine, G. (1963). Familial alobar holoprosencephaly (arhinencephaly) with median cleft lip and palate. Report of patient with 46 chromosomes. Neurology (Minneap.), 13, 913.

Dill, F. J., and Miller, J. R. (1963). Personal communication to Uchida et al. (1965).

Faint, S., and Lewis, F. J. W. (1964). Presumptive deletion of the short arm of chromosome 18 in a cyclops. Hum. Chromos. Newsl., 14,5 .

Haworth, J. C., Medovy, H., and Lewis, A. J. (1961). Cebocephaly with endocrine dysgenesis. Report of 3 cases. f. Pediat, $59,726$.

Hickox, D. B. (1964). Personal communication to Uchida et al. (1965).

Klopstock, A. (1921). Familiäres Vorkommen von Cyklopie und Arrhinencephalie. Mschr. Geburtsh. Gynäk., 56, 59.

Landau, J. W., Barry, J. M., and Koch, R. (1963). Arhinencephaly. F. Pediat., 62, 895.

Lewis, F. J. W., Poulding, R. H., and Woods, G. (1963). Personal communication to Uchida et al. (1965).

Salmon, Ch., Ropartz, C., de Grouchy, J., Lejeune, J., Salmon, D. Rivat, L., Rousseau, P. Y., Liberge, G., and Delarue, F. (1966). Exclusion de certaines localisations autosomiques des gènes de groupes sanguins et sériques. Ann. Génét., 9, 9.

Snodgrass, G. J. A. I., Butler, L. J., France, N. E., Crome, L., and Russell, A. (1966). The 'D' (13-15) trisomy syndrome: an analysis of 7 examples. Arch. Dis. Childh., 41, 250.

Summitt, R. L. (1964). Deletion of the short arm of chromosome 18. Cytogenetics, 3, 201.

Uchida, Irene, A., McRae, K. N., Wang, H. C., and Ray, M. (1965). Familial short arm deficiency of chromosome 18 concomitant with arhinencephaly and alopecia congenita. Amer. F. hum. Genet., 17, 410.

Van Dyke, H. E., Valdmanis, A., and Mann, J. D. (1964). Probable deletion of the short arm of chromosome 18. ibid., 16, 364 . 